\title{
O LIBERALISMO COMO SABEDORIA POLÍTICA
}

\author{
João da Cruz Gonçalves Neto
}

\begin{abstract}
RESUMO - O objetivo deste artigo é contextualizar, sinteticamente, o liberalismo da Teoria da justiça de John Rawls dentro da tradição, a partir de alguns de seus elementos essenciais, tais como as idéias de contrato, de liberdade, de igualdade e de racionalidade, e identificá-lo a uma forma própria e metódica de se pensar a política como sabedoria

PALAVRAS-CHAVE - Liberalismo. Teoria da KEY WORDS - Liberalism. Theory of justice. John justiça. John Rawls.

ABSTRACT - The aim of this article is to summarily contextualize the liberalism of Rawls's A Theory of Justice, within the political tradition and its essential elements, such as the ideas of contract, liberty, equality, and rationality, so as to identify its proper form and method to think politics as wisdom. Rawls.
\end{abstract}

\section{O que é ser liberal?}

A tarefa de dispor sob um mesmo nome uma tradição tão díspar e espontânea, como é a do liberalismo, é de uma pretensão bastante arriscada por ser necessariamente redutora. Unânime, entre os que se autodenominam liberais, talvez seja somente a discordância ostensiva sobre a maior parte dos problemas que a tradição costumou reunir às idéias de democracia, liberdade e igualdade.

Waldron, em seu belo ensaio Theoretical Foundations of Liberalism, depois de considerar a dificuldade de apresentar as características comuns ao que tradicionalmente se entende por liberalismo, reduz sua pretensão a demonstrar

[...] que os liberais estão comprometidos com uma concepção de liberdade e com o respeito às capacidades e ações de homens e mulheres individuais, e que esses comprometimentos geram uma necessidade de que todos os aspectos do social devem ser feitos aceitáveis, ou ser capazes de serem feitos aceitáveis para todo e qualquer indivíduo (Waldron, 1987, p. 128). ${ }^{1}$

\footnotetext{
Universidade Católica de Goiás - UCG.

"Briefly, I shall argue that liberals are commited to a conception of freedom and of respect for the capacities and the agency of individual men and women, and that these commitments generate a requirement that all aspects of the social should either be made acceptable or be capable of being made acceptable to every last individual."
}

\begin{tabular}{|l|l|l|l|l|l|}
\hline VERITAS & Porto Alegre & v. 52 & n. 1 & Março 2007 & p. 94-107 \\
\hline
\end{tabular}


O que aqui se aponta como um importante traço distintivo, partilhado pela maioria das posições liberais, é o compromisso com a liberdade, a partir de uma certa concepção de indivíduo, que o toma como o centro da dinâmica social, e que deve ter na sociedade uma espécie de espelho de si. A distância entre as visões liberais se daria muito no relacionamento do homem com seu reflexo (a sociedade), seja na forma como este é estabelecido, na interpenetração das várias representações possíveis, na ênfase ou na direção da ação política. O liberalismo pressuposto na Teoria da justiça tem a pretensão de contornar uma das principais críticas dirigidas a essa tradição que é precisamente a de possuir uma visão imatura e insuficiente da sociedade, própria de uma simples ideologia necessária ao capitalismo. Como desenvolvida por Rawls em sua obra, uma visão de justiça igualitária não permite, de forma alguma, uma concepção de indivíduo como encontramos, por exemplo, em Locke. Se, para este, a sociedade é resultado de um contrato privado, do qual participam indivíduos nascidos prontos, como que adultos, com uma consciência cultural sem jamais terem vivido em alguma cultura, ${ }^{2}$ para Rawls os interesses individuais são necessariamente mediados pela sociedade, não só em termos de oposição, mas de sua própria constituição. Para muitos, essa abordagem é considerada um avanço na filosofia política anglo-saxônica; para outros, Rawls não pode nem mesmo ser considerado um liberal. No que segue, faremos uma breve contextualização do liberalismo político do autor americano, a partir dos problemas mais comuns em debate na tradição. Comecemos com o problema da liberdade.

\section{A liberdade}

Embora haja liberais que afirmem ser a igualdade o centro do domínio liberal, a maioria se diz comprometida prioritariamente com a idéia de liberdade. Esta, naturalmente, pressupõe uma complexidade analítica gigantesca, e envolve várias outras questões abstratas, axiomáticas, e que fazem parte de perene disputa filosófica, tais como as noções de vontade, causalidade, consciência individual, responsabilidade, etc. A forma como se desenrola a dinâmica social, concebida por nossa cultura ocidental moderna e por grande parte de seus justificadores, é como se a sociedade fosse um grande palco onde indivíduos-atores exercessem seus papéis, hipoteticamente sem base em nenhum script prévio; ${ }^{3}$ depois de viver,

2 O estado de natureza em Locke pressupõe a visão cristã de indivíduo, e é portanto tomado como uma unidade que é lançada no mundo, no meio do tempo, e que deve buscar se conduzir inteligentemente entre outros seres. Sua consciência é do tamanho de seu mundo e anterior a ele, sem implicação mútua entre um e outro senão pelas constrições naturais à vida e ao conhecimento estabelecido por um modelo fixo e unilinear (ou seja, o mundo oferece possibilidades, mas não há possibilidades a ele). Ver o Segundo tratado sobre o governo, in LOCKE, J. Os pensadores, vol. XVIII. São Paulo: Abril S.A., 1973. Ver também o esclarecedor artigo sobre a gênese do moderno conceito de ser moral ou pessoa, em ZARKA, Yves. "A invenção do sujeito de direito". In: Filosofia Política. Porto Alegre: LPM editores, 1997, p. 22-24.

3 Um belo estudo em psicologia social sobre o tema da representação dos papéis sociais é GOFFMAN, Erving. A representação do eu na vida cotidiana. Petrópolis: Vozes, 1985. 
jornadas intermitentes, essa parcela artificial de sua existência, não-espontânea, onde a vida se desenrola e se ganha numa competição contra os outros, os indivíduos então retornam para o seu estado de natureza, o espaço fragmentado, não submetido a certo nível de comandos públicos, que é uma reserva do mundo onde podem ser os tiranos de um reino particular, o reino do domínio privado. Sob esse cenário mais ou menos comum, tomado como substancial ou metodológico, os conceitos fundamentais vão ser arranjados de forma a definir as posições que comporão um importante mosaico de dissonâncias e afinidades.

A liberdade é um tema extremamente complexo. Não se pode querer decompô-lo como uma definição fixa, objeto próprio e perene de análise filosófica. Sua análise se abre em inúmeras outras acepções igualmente complexas. Mas, para a tradição que tem como uma das características centrais o pragmatismo, é a base da cultura que fornecerá os principais elementos para a constituição do debate.

$\mathrm{Na}$ área econômica, os termos argumentativos repousam essencialmente na oposição entre o que seja o interesse privado e o interesse público, e o confronto entre a liberdade de ação do indivíduo e a do Estado - o representante dos interesses coletivos. Alguns liberais afirmam que o Estado é um mal radical, o que os aproxima dos anarquistas, e que qualquer imposição, em nome da coletividade, sob qualquer pretexto, é uma agressão à liberdade individual; outros concedem alguma interferência da sociedade na liberdade dos indivíduos, mas entendem que a ação coletiva deve estar sob constante tutela, e deve ser o suficiente para manter a paz, a ordem, a liberdade de ação individual, e podem aceitar ainda políticas compensatórias (os liberais clássicos partilham, em geral, dessa visão); há ainda os que submetem a liberdade econômica dos indivíduos a critério não-contingencial, não-espontâneo, como a justiça política, que pressupõe alguma forma de centralismo político na gestão dos interesses sociais (como é o caso de Rawls, o que o faz parecer, para alguns, um não-liberal).

Quanto à moralidade, o espírito liberal vê comumente o comportamento do indivíduo como se opondo a todo tipo de autoridade, traço distintivo do obscurantismo medieval, e tem como ideal regulativo a espontaneidade das relações, relações essas ordenadas precipuamente pela tradição continuada. É que para essa visão de mundo, o comportamento adaptativo, pelo menos na maior parte das ocasiões, é mais confiável que o enquadramento feito por qualquer modelo racional, que, por mais desenvolvido que seja, sempre terá fora de si uma complexidade inapreensível, ou compreensível, mas não a ponto de fundamentar a ação conseqüente. Essa é a expressão da sabedoria aristotélica "na dúvida, segue a tradição", com a diferença de que para aqueles a dúvida costuma ser fundamental, e não uma simples e momentânea insegurança no cálculo que ambiciona controle. Assim, em termos de política pública, os liberais costumam ser comprometidos com as liberdades civis, de crença religiosa, de escolhas sexuais, intelectuais, etc., liberdades essas que têm uma conexão especial com o problema da ordem social, outra questão vinculada à idéia de liberdade.

A opção liberal, grosso modo, está entre a que defende que a liberdade é a total submissão às leis justas de uma boa sociedade, e a total emancipação da or- 
dem social estabelecida, numa espécie de anarquia. O meio-termo, como penso que seja a posição dominante, é que a ordem social se objetiva ao juízo dos indivíduos como passível de conhecimento e de atuação, de maneira que a liberdade seja mantida como a liberdade individual de se reservar o espaço de isenção política e cognoscitiva, que é o espaço privado, para então escolher e atuar sobre o arranjo social que coletivamente se deseje. Assim, quando o indivíduo é visto como aquele que pode escolher a sociedade na qual viverá, com suas restrições e compensações, contornam-se as posições extremas, fazendo-se da liberdade uma decorrência natural das concepções de indivíduo e sociedade.

Outra forma de abordagem ao tema da liberdade é a que a relaciona à idéia do sujeito cognoscente individualizado, com sua vontade em vínculo com a capacidade, alcance e natureza do agir. Destacamos, sinteticamente, dois pontos: o primeiro, o problema do sujeito da liberdade e a relação entre sua vontade e ato. Já falamos um pouco da relevância da idéia da espontaneidade na tradição liberal, e notaremos que ela desempenha um papel igualmente importante, como complexo, também no campo da ação individual. A questão envolvida é a de quem é o verdadeiro sujeito da liberdade, ou mesmo se há esse sujeito verdadeiro submerso a ser emancipado. Essa é uma disputa perene, e traz para a política as profundezas especulativas da ética e da metafísica. Para a tradição liberal, pragmática na origem, o que interessa, antes de qualquer abstração, é a concepção do indivíduo a partir de sua atualidade, ou seja, a partir da consciência de si mesmo no momento em questão (Waldron, 1987, p. 132), ${ }^{4}$ que será então o elemento primeiro do edifício político, erigido com o mínimo de idealizações. De outra forma, o sujeito da liberdade estaria condicionado a uma concepção na qual não caberia a liberdade nos termos em que é entendida pela cultura ocidental moderna. É exatamente esse ponto, o de fazer da liberdade uma concepção convencional e contingencial, que a maioria dos críticos não liberais atacarão, e penso que com bastante propriedade. Afinal, ainda que se resolva metodologicamente o problema da busca indefinida por fundamentos sólidos à ação política, será sempre um problema que implicará modificações finais à compreensão da própria política.

Mas, de volta à questão do sujeito da liberdade, a posição liberal será intermediária entre aquele que assume a coletividade como sujeito de liberdade e a que afirma no indivíduo a base natural da liberdade, porém que historicamente dela não se apropria por uma série de limitações à emancipação. Como já afirmamos, o verdadeiro sujeito da liberdade que interessa ao liberal é mais um sujeito metodológico que "verdadeiro", no sentido de ser compreendido como decorrência de uma apreensão sistêmica da dinâmica social. Assim, a consciência individual, a causalidade entre a vontade individual e a ação, a moralidade fragmentada em regras e normas individuais, a responsabilidade individual assumida como unidade

"To talk about my freedom, on the liberal view, is to talk about the role I play in the determination of my actions, where ' $\mathrm{I}$ ' is understood in the sense of what it is now like to be me; it is not to talk about the thought or decision-making of an entity cleansed of the 'false consciousness' that characterizes my present experiences and desires." 
primária que estrutura a ação pública, são todos elementos que compõem a concepção liberal de mundo.

O segundo ponto bastante relevante é o que associa a liberdade à ação, que especula sobre o alcance de nossas ações e o que implica buscar a medida e a possibilidade de nossa autonomia. O liberalismo, como o marxismo, é filho do racionalismo moderno, do otimismo em conhecer o mundo e em compreender, mudar e controlar a vida social, a partir de regras extraídas da observação desmistificada dos fatos, das relações humanas, da história. O ponto polêmico, tanto entre os liberais como entre os não-liberais, é em que medida pode ser dado esse controle sobre a própria vida, e se o aparato científico pode compreender toda a complexidade do mundo, no presente e na história. Os liberais costumam ser mais ou menos céticos quanto à possibilidade de se compreender a gigantesca complexidade dos fatos humanos e da realidade, e tomam como uma pretensão exagerada e inocente o ímpeto de, a partir de esquemas racionais, controlar a vida política e social (os matizes se deslocam dos neoliberais aos liberais sociais). A liberdade, em si benéfica, por acompanhar a natureza, a espontaneidade e o incompreensível (ao estilo de Edmund Burke: "Não, nunca, disse a natureza uma coisa e a sabedoria outra"), é ameaçada individual e coletivamente, toda vez que se tenta agir positivamente sobre o conjunto das ações humanas, e tanto mais grave quanto mais abrangente for a ação política. A idéia é que o pensamento e a ação, quando tomam como objetos a completude do mundo, a saber, a vida, a dinâmica social, as relações individuais, que é inapreensível pelo status atual de nosso conhecimento, exclui naturalmente a possibilidade de se conhecer o que já não está previamente modelado, e isso é tolhimento de liberdade, assim considerada como essa disponibilidade criativa supramodelar. Eis a concepção fundante, como penso, da distinção entre a liberdade dos antigos, a positiva, que é a atribuição de poderes aos cidadãos na configuração política democrática, e a liberdade dos modernos, que é o espaço de ação não-normativo, individual e vinculado ao que se chama de direito subjetivo. A liberdade negativa é, então, a abertura para o que ultrapassa a consciência política, a possibilidade de compreensão, a hipótese metodologicamente situada de que a história guarda sempre muito mais do que agora podemos ver, a despeito de ser somente sobre o que agora podemos ver e ser é que podemos erigir regras de ação.

Nesse amplo espectro de problemas que envolve a idéia de liberdade, a obra de Rawls vai ocupar um lugar mais à esquerda no display de idéias, exatamente por levar em conta, e com isso, "dar um passo adiante" (Rawls, 2000a, p. 358) na tradição liberal quando conecta a concepção de pessoa à de cooperação social. Tentemos explicitar essa posição.

"The point of introducing the conception of the person I have used, and its companion conception of social cooperation, is to try to carry the liberal view one step further: that is, to root its assumptions in two underlying philosophical conceptions and then to indicate how the basic liberties with their priority can be regarded as belonging among the fair terms of social cooperation where the nature of this cooperation answers to the conditions these conceptions impose" (Rawls, 1996, p. 304). 
Em sua obra de ampliação e reparação da Teoria da justiça, O liberalismo político, Rawls apresenta a sua visão histórica do liberalismo (também apresentada com mais desenvolvimento na introdução de suas Lectures (Rawls, 2000c, p. 118), bem como o problema central a que deve se dirigir o esforço político. A seu ver, o problema central do liberalismo é o de compreender como é possível existir uma sociedade justa e estável, que tem como princípio constatativo o fato de as pessoas sempre partilharem de doutrinas políticas, religiosas e filosóficas irreconciliáveis, e qual seria a estrutura e o teor dessa concepção política (Rawls, 2000a, p. 25-26). ${ }^{6} \mathrm{O}$ problema político da modernidade é assim estabelecido em confronto com as condições que a antecederam, e que fizeram do liberalismo a resposta espontânea ao problema acima citado. Em confronto com a visão de mundo autoritária, centralizada, e cujo bem se dava a conhecer exclusivamente pela religião, relegando à vida política o embate pelas convicções particulares desse bem, surge a nova demanda, precipitada pela Reforma, pelo desenvolvimento do Estado e pela ciência moderna, da unificação na política da busca do problema das condições essenciais de uma sociedade viável e justa com a admissibilidade da pluralidade de bens. Essa, sim, é a novidade central na política moderna, e o porquê de Rawls identificar, como pensamos, o liberalismo à própria política. Pois é exatamente nesse espaço que se abre entre uma nova concepção de política, agora como a catalisadora das condições formais da vida social, e a nova concepção de indivíduo, como alguém que dissocia a busca de seu bem das condições de vida comum, cuja verdade justificadora passa a ser emparelhada à de outros, é que nasce a primazia da liberdade como um pressuposto condicional da própria convivência justa. A liberdade é o que assegurará, por um lado, a convivência estável e o respeito à diferença mutuamente reconhecidos, e, por outro, a garantia de que a vida pública, por ser regulada por concepções não-substanciais (por exemplo, o conteúdo de uma concepção de mundo particular), será dinâmica e estará aberta à complexidade dos problemas humanos da única forma possível dentro de uma condição histórica dada. A partir dessa condição geral do liberalismo, podemos especificar alguns elementos da concepção de liberdade na Teoria da justiça de Rawls.

\section{Liberdade e igualdade}

Conforme pensamos, não existe para Rawls uma preeminência da liberdade sobre a igualdade, ou vice-versa. Na verdade, uma decorre da outra, e não se justificariam, se não fosse mutuamente. Tal fato ocorre por, no contexto da Teoria da justiça, não haver nenhum tipo de conteúdo valorativo preestabelecido que se justificasse a partir de alguma visão de mundo particular. Embora as pressuposi-

\footnotetext{
"The main conclusion to draw from these remarks [...] is that the problem of political liberalism is: How is it possible that there may exist over time a stable and just society of free and equal citizens profoundly divided by reasonable thought incompatible religious, philosophical, and moral doctrines?" (Rawls, 1996, p. xx)
} 
ções do sistema considerem uma teoria das instituições sociais e alguma consideração histórica, elas são tomadas no que se abstrai da contingência e se aplica no contrato. Dessa forma, a liberdade não possui um conceito fixo ou um valor prioritário, preeminente e racional, mas antes é um valor construído, deliberado sob certas condições, em determinado contexto. Ela depende, em conformidade com o primeiro princípio (Rawls, 2000a, p. 345), ${ }^{7}$ de um sistema de condições orientado para a justiça, que pressupõe a liberdade ou igualdade entre seus elementos. Não é, portanto, um objeto filosófico privilegiado que possa ser analisado ao longo do tempo, independentemente da tradição na qual se insere. O liberalismo pede uma filosofia política própria para si.

Mas se não temos elementos substantivos para definir a liberdade, como se poderia esperar de uma definição positiva de que forma poderíamos caracterizála? Rawls o fará, a partir de uma definição contextual, discutindo a liberdade em conexão com limitações legais e constitucionais, como se fosse uma certa estrutura de instituições, um certo sistema de normas públicas que definem direitos e deveres. Sua descrição geral seria: "Esta ou aquela pessoa (ou pessoas) está (ou não está) livre desta ou daquela restrição (ou conjunto de restrições) para fazer (ou não fazer) isto ou aquilo" (Rawls, 1997a, p. 219). ${ }^{8}$ Na expressão de Constant, ${ }^{9}$ essa seria a configuração da liberdade negativa dos modernos. Ela se resolve (no âmbito abstrato da posição original) na deliberação, não por um estado ontológico ou psicológico, mas a partir de uma lista de bens primários, que compreende "insumos" materiais, psicológicos e políticos. Historicamente situado, esse ponto de partida converte-se em um realinhamento moral de nossa tradição, que é de um liberalismo oportunista, ${ }^{10}$ ideologicamente assentado em uma concepção de pessoa tomada como responsável pelas conseqüências pessoais do desajuste social, mas não pelo eventual êxito na busca por justiça.

\section{Pessoa e cooperação social}

No modelo da justiça como eqüidade, as partes são concebidas como dispostas em simetria, o que equivale à situação da igualdade, como deliberantes que se emanciparam da contingência histórica, o que representa os requisitos da liberdade, e estão inseridas em condições especiais (a justiça como eqüidade) que as

\footnotetext{
"a. Each person has an equal right to a fully adequate scheme of equal basic liberties which is compatible with a similar scheme of liberties for all" (Rawls, 1996, p. 290).

8 "The general description of liberty, then, has the following form: this or that person (or persons) is free (or not free) from this or that constraint (or set of constraints) to do (or not to do) so and so" (Rawls, 1997b, 202).

9 Veja: CONSTANT, B. "Da liberdade dos antigos comparada à liberdade dos modernos" In: Filosofia Política. Porto Alegre: LPM, 1985.

10 Liberalismo oportunista: a pessoa é concebida como anterior e incólume às determinações sociais. Só assim ela pode ser juridicamente imputável, moralmente responsável, e intelectualmente fragmentada entre um palco público racional e um bastidor privado emocional, bastidor esse onde geralmente explodem as contradições e violências tomadas como naturais pelo enquadramento ideológico vigente.
} 
tornam necessariamente cooperativas, o que corresponde à união ideal de cooperação social e interesse próprio.

A noção de pessoa utilizada pelo modelo é a usual da tradição: o eu que se imagina neste momento, e não um ideal qualquer que o substitua. Na Teoria, isso é feito apagando, com um véu de ignorância, a cisão entre o que seja ideal e o que seja a realidade histórica, mas mantendo como condições de deliberação todo o conhecimento histórico e científico em nível de generalidade, o que condiciona e vincula os conceitos políticos à tradição democrática ocidental. A pessoa, a parte, dessa forma, não pode ser concebida sem a sua implicação social, sem a forma social que a antecedeu, representada pela própria concepção do modelo. É esse o passo que Rawls diz ser, na introdução de seu Liberalismo político, o passo adiante na tradição liberal. O bem do indivíduo está antecedido pelas condições de deliberação pública e privada, o que condiciona a busca dos interesses e dos bens privados aos públicos, embora de uma forma flexível e problemática. Nessa concepção, o indivíduo tanto é moldado como é forjador de sua realidade social; ele faz parte de um mecanismo político por excelência que tenta se apropriar de um conhecimento coletivo (e não só da deliberação e ação coletivas), e ao mesmo tempo agir dentro do escopo o mais realista e reflexivo possível.

\section{Liberdade individual e social}

A questão de se devemos considerar prioritariamente a liberdade individual ou a do grupo é tradicionalmente rica em confronto entre os liberais, e agudamente problemática entre os liberais e não-liberais. Muito da discussão deve-se à concepção de pessoa, uns a considerando como o único motor da dinâmica social, outros como um simples produto final de uma dinâmica que compreende toda a sociedade na história, e entre esses extremos encontraremos as posições liberais bem mais interessantes, entre as quais se situa a do autor americano.

Rawls é um racionalista que quer passar a modernidade a limpo. Meticuloso, desconfia de todo esforço que já não se tenha submetido ao exame histórico e da ponderação atual; erige uma obra que tenta catalisar toda a capacidade reflexiva na política para dispô-la à ação pública. Sendo um racionalista, o autor da Teoria da justiça não pode simplesmente aceitar uma asserção substantiva pelo simples fato de parecer bastante convincente, como quando se pensa que há uma ordem social espontânea e benéfica que a tudo coordena em prol da justiça e da eficiência econômica, ou então quando se crê que a capacidade humana coletiva de compreender a si mesma e o mundo, na atualidade, seria sempre suficiente para conduzir a vida social com justiça, equilíbrio e tolerância. Não, a ponderação pela justiça (o maior dos valores coletivos) o fará buscar uma alternativa mediana. Afirmar que o justo precede o bem num ambiente de deliberação política é exatamente superpor os interesses coletivos aos individuais, reformulando a concepção de indivíduo que se afirma na vida social prática do Ocidente, que sempre se posicionou como um presente, mas longínquo ideal político. Kantianamente falan- 
do, a liberdade é agir de acordo com as leis elaboradas por quem deve se submeter a elas.

Quando falamos em reformulação da concepção de pessoa, temos firmeza de que Rawls não faz concessão a nada menos que uma revolução moral, quando se toma o estabelecimento atual como referência. No modelo da justiça como eqüidade, ter indivíduos que deliberam numa situação de contrato não é assumir integralmente o individualismo metodológico por princípio, numa acepção hobbesiana de sociedade. É assumir que, na prática, há uma espécie de conhecimento, de reflexão, de crítica que não se forma nos indivíduos, e só com eles. A instância política, a da deliberação sobre a vida, é a que, ao mesmo tempo, condiciona e é condicionada. O indivíduo, na posição original, equivale ao cidadão numa sociedade democrática ideal, que a concebe criticamente e pode corrigir seu curso histórico, em acordo com a vontade dos outros indivíduos; por outro lado, é um indivíduo condicionado pela interação, pela cultura, pelas condições naturais, mas que, por ser politicamente maduro, compreende ou tenta compreender essas condições e limites. Se o indivíduo é tomado como o ponto de partida da motivação política, como o centro e princípio da ação pública, não é pelo fato de não se considerar como concreta ou suficiente qualquer demanda pública ou ser qualquer objeto sociológico epistemologicamente válido; antes, é por respeitar exatamente a vida humana como sagrada, como fim, como não-objeto de barganha, o que se traduz pelo igualitarismo. Todo indivíduo é depositário de um valor essencial, que o arranjo social e a contingência histórica, sob nenhuma hipótese, pode lesar ou compensar. Daí se antepor o justo a qualquer fim, individual ou coletivo. Se os fatos naturais são desprovidos de sentido moral, como a cobra comer o rato ou um indivíduo ser maior, mais astuto ou mais forte que outro, socialmente (e o indivíduo só pode ser concebido em uma sociedade) se instauram (constroem) os valores que no palco da vida deverão se inter-relacionar. Nenhum indivíduo merece os seus dotes inatos (Rawls, 1997a, p. 111, 343), ${ }^{11}$ pois esses dotes só teriam sentido e valor no grupo. A moralidade requerida para esse liberalismo não é a que se esquece da sociedade depois de ela ser útil ao indivíduo; é uma moralidade que leva a sério o indivíduo no que ele não tem de performático, naquilo que não está em jogo, mas que se vincula à própria vida. Esta não pode, de forma alguma, ser contabilizada, contar-se entre os outros valores; enfim, não pode fazer parte da barganha. Assim, a classificação por mérito, próprio de uma moralidade que sim-

11 "Perhaps some will think that the person with greater natural endowments deserves those assets and the superior character that made development possible. Because he is more worthy in this sense, he deserves the greater advantages that he could achieve with them. This view, however, is surely incorrect. Is seems to be one of the fixed points of our considered judgements that no one deserves his place in the distribution of native endowments, any more than one deserves one's initial starting place in society. The assertion that a man deserves the superior character that enables him to make the effort to cultivate his abilities is equally problematic; for his character depends in large part upon fortunate family and social circunstances for which he can claim no credit."(Rawls, 1997b, p. 103-104); "[...] It simply reflects the fact noted before (§ 17) that it is one of the fixed points of our moral judgments that no one deserves his place in the distribution of natural assets any more than he deserves his initial starting place in society" (Rawls, 1997b, p. 311). 
plesmente justifica o jogo do poder estabelecido, é absolutamente rejeitada. O equivalente na moralidade cristã da moral, que cria a idéia de responsabilidade individual, para firmar o indivíduo à estrutura social poderia ser: "Você vai para o céu só pelo fato de existir; mas terá uma sala vip, se superar todos os outros, humilhando-os". Por outro lado, Rawls não permite a confusão entre a liberdade e o valor da liberdade. Se esta deve ser assegurada politicamente, o Estado não deve ser paternalista a ponto de forçar alguém a ser livre. Pode, no entanto, dar condições (por exemplo, através da educação) aos indivíduos para se fazerem cidadãos autonomamente.

Em conclusão, notamos que a moralidade implicada pela Teoria da justiça não é uma moral tradicionalmente concebida por um largo grupo de pensadores, e nem tampouco pelo senso comum dominante do Ocidente moderno. Rawls incorpora a análise sociológica à sua concepção de indivíduo e sociedade, e dá à liberdade uma noção, conforme pensamos, mais consistente, e que talvez possa ser assim esquematizada: ao indivíduo, ser livre é ter consciência das próprias limitações naturais, sociológicas e históricas, e poder agir em conformidade com o grupo para o interesse próprio ou coletivo, conforme a distância de seus fins. Isso porque em uma sociedade justa o papel político do indivíduo seria só de atenção ao funcionamento das instituições e de ajuste dos fatos novos não-incorporados na visão da política deliberada; a estrutura social justa é a única que permite a liberdade. Ao contrário, é o estado de guerra.

\section{A racionalidade}

Para Rawls, o ponto de partida metodológico do esforço político, teórico ou prático, é o de nos atermos à racionalidade que reconhece seus limites como o guia mais fiável para a ação, unida à razoabilidade, faculdade própria da sociabilidade.

O Iluminismo foi caracterizado por uma confiança burguesa na habilidade humana em fazer sentido do mundo e da sociedade, coisa que o empirismo transformou em otimismo no interesse da mente individual - o indivíduo, e só ele, poderia entender o mundo (Waldron, 1987, p. 135). ${ }^{12}$ A razão, de mãos dadas com a ordem universal, deu confiança inédita à cultura, no confronto com a tradição, a autoridade, a fortuna, o mistério. De lá para cá, a filosofia política e a razão liberais tornaram-se menos altivas, e com Rawls, como pensamos, elas tentam pôr os pés no chão. Isso porque a segurança que outrora era buscada na natureza e na metodologização do saber mostraram-se insuficientes para compreender a dinâmica social a ponto de assegurar a correção das ações. Como a história mostrou doloro-

12 "After millenea of ignorance, terror, and superstition, cowering before forces it could neither understand nor control, mankind faced the prospect of being able at last to build a human world, a world in which it might feel safely and securely at home. Empiricism made this an optmism on behalf of the individual mind: there was a sense abroad that is was possible, in principle, for each individual to understand the world in this way, and indeed is was maintained that there was no other way in which the world could be understood except by an individual mind." 
samente (e como igualmente insiste em continuar em nossos dias, de forma talvez mais perversa e cruel), esse otimismo converteu-se no sonho da autoridade, da opressão, do poder justificado por uma racionalidade identificada à totalidade do conhecimento humano aplicada a uma contingência histórica.

Para a filosofia política de nossos dias, a racionalidade tornou-se instrumental, perdendo sua intimidade com o universo, e reconheceu a vida humana em meio a uma forma de autismo político que desconhece o que se pode esperar do mundo e de si mesmo, mas que possui um conhecimento limitado, crescente, porém não muito mais que isso, no momento histórico no qual se encontra. Para os objetivos políticos, a racionalidade pode ser limitada, como é no modelo da Teoria da justiÇa, ao padrão na teoria política, que é o de se adotar os meios mais eficientes para determinados fins (Rawls, 1997a, p. 15 e 154). ${ }^{13}$ Tornou-se, então, um conceito simplesmente operacional, deixando todo o processo de intelecção política à sua junção com outras faculdades, ao longo do tempo, numa realização histórica gradual e indefinida.

\section{O contrato social}

Conforme declarado na introdução de Uma teoria da justiça, o filósofo americano teve como objetivo "generalizar e elevar a uma ordem mais alta de abstração a teoria tradicional do contrato social representada por Locke, Rousseau e Kant". Mais precisamente, foi a de expor uma concepção de justiça implícita na tradição contratualista e "apontar o caminho para uma elaboração maior dessa tradição" (Rawls, 1997a, p. XXII-III). ${ }^{14}$

Mas o que seria essa elevação do nível de abstração da teoria contratual? Para os clássicos contratualistas, temos na idéia de contrato uma função retórica tremendamente importante que deu a ela grande força de sentido, que foi apresentar uma alternativa convincente à também retórica tradicional justificação do poder. A idéia central era a de que a autoridade não se justificava naturalmente, que o poder pelo poder era fruto de uma equivocada contingência histórica, e que os indivíduos, no seu relacionamento espontâneo com o mundo, eram iguais, rei ou servo, pois só a vida social, vista como um acidente, fruto da obra humana e passível de ser mudada, era que assegurava as diferenças e, mais importante, assegurava a plausibilidade dos valores dominantes. A visão social do contrato, portanto, tomava a sociedade como uma união privada de indivíduos, que ingres-

13 "Moreover, the concept of rationality must be interpreted as far as possible in the narrow sense, standard in economic theory, of taking the most effective means to given ends (Rawls, 1997b, p. 14). "The concept of rationality invoked here, with the exception of one essential feature, is the standard one familiar in social theory. Thus in the usual way, a rational person is thought to have a coherent set of preferences between the options open to him. He ranks these options according to how well they further his purposes; he follows the plan which will satisfy more of his desires rather than less, and which has the greater chance of being successfully executed" (Rawls, 1997b, p. 143).

14 "My ambitions for the book will be completely realized if it enables one to see more clearly the chief structural features of the alternative conception of justice that is implicit in the contract tradition and points the way to its further elaboration" (Rawls, 1997b, p. viii). 
savam hipoteticamente em estado de igualdade num consórcio para o benefício de todos. O pressuposto da igualdade é que será a novidade histórica, demonstrada (conjecturada) pela oposição entre a natureza humana e a natureza exterior, e entre a natureza humana e o processo histórico. Em primeiro lugar, o homem desliga-se da natureza, para criar seu próprio mundo; nesse processo de criação, ele pode equivocar-se, pode perder-se em seu caminho na história. Pensar politicamente seria relembrar o que motivou a instauração do mundo humano, retomar o ímpeto inicial que fez com que os indivíduos preferissem a vida em grupo, e desvelar os equívocos que o hábito, com o tempo, escondeu.

Elevar essa idéia a um nível maior de abstração é buscar uma justificação diferente para a igualdade, a liberdade e a sua forma de exercício político, a democracia. O apelo agora não será para a natureza, ou para o conhecimento moderno sobre ela ou sobre os homens, ou ainda alguma intuição muito convincente. Como é praticamente pacífico para toda a tradição liberal que a ordem social deve ser necessariamente justificada a todos que a compõem, o contrato, na Teoria da justiça, é imaginado dentro de uma experiência de pensamento com a função principal de construir uma justificativa de uma ordem social justa que tem como condições aqueles valores idealizados da tradição política ocidental. O modelo parte de premissas que podemos aceitar realmente ou deveríamos aceitar mediante um raciocínio apropriado, conforme as regras habituais de reflexão (Rawls, 1997a, p. 24). ${ }^{15}$ Coerência interna, retorno intuitivo às idéias fundantes de nossa cultura e simplicidade são os meios de que dispõe o modelo. Eis o porquê de se buscar pela fundamentação da justiça, ao invés de buscar os elementos da ordem social, conforme os requisitos da tradição. Simplesmente nenhum valor político substancial pode ser convincentemente assegurado, por mais arraigado na tradição ele esteja; como é próprio aos liberais, podem-se sempre esperar-se bons argumentos em contrário.

O recurso à idéia de contrato como fundamento da ordem social democrática traz também as questões da escolha, se ela deve ser real ou pode ser hipotética. Rawls assume integralmente a posição de Kant, e todo o seu modelo de pensamento é fundado sobre esse pressuposto, o de que considera legítima a ordem que se funda nas regras de racionalidade e razoabilidade sob um ponto de vista histórico, e não simplesmente contingencial. Esse autor assume a noção de razão política liberal, razão essa que julga poder comportar outros tipos de racionalidade por não assumir como questão de princípio qualquer definição substancial. As diferenças normalmente são tomadas como acidentais, frutos da liberdade humana e da dificuldade em se lidar com ela. Dessa forma, o juiz de um sistema político é essa razão incorporada nas instituições, a razão pública, e não a razão do público como simples expressão de vontade. Portanto, a deliberação democrática não tem que necessariamente partir de um consentimento real, mas tem que ser hipotéti-

15 "It is natural to ask why, if this agreement is never actually entered into, we should take any interest in these principles, moral or otherwise. The answer is that the conditions embodied in the description of the original are ones that we do in fact accept" (Rawls, 1997b, p. 21). 
ca, representativa. A legitimidade e a obrigatoriedade são, então, explicadas pela justificativa racional e pela assunção, ou a possibilidade de se assumir as instituições que refletem a ordem em conformidade com a razão pública.

\section{Considerações finais}

O liberalismo de Rawls, assim como outras formas de liberalismo, tem como fonte principal de sua justificativa epistemológica a tradição política ocidental com seus elementos amplamente partilhados em certa atualidade. Muitas doutrinas igualmente apóiam-se na firmeza da genialidade motivada pelos ideais de seus escritores, em belos trabalhos de fundamentação epistemológica, tais como os de Hayek, Popper, Nozick e outros.

Duas características, entretanto, fazem do liberalismo político como Teoria da justiça um modelo apropriado para uma teoria normativa do conhecimento político, como pretendemos. A primeira é que a Teoria da justiça é uma teoria metodológica voltada essencialmente para a forma política, ainda que tenha como meta prioritária a fundamentação de princípios de justiça. Na verdade, para se fundar esta ou outra qualquer concepção de justiça prevista como possível, na estrutura da obra do autor americano, os pressupostos metodológicos da justiça como eqüidade poderiam ser certamente os mesmos para aquelas concepções que partem dos ideais da modernidade política ocidental (por exemplo: racionalidade, igualdade, individualismo, capacidade de mudar o próprio caminho histórico, etc.). Com isso, Rawls tenta realizar um modelo que se apóia em elementos cognoscitivos metodologicamente abrangentes, de alcance cultural. O modelo da justiça como eqüidade, assim, traduz e esquematiza um certo tipo de reflexão pública, fazendo do âmbito do político o fórum específico de constituição dessa teoria que necessariamente metodologiza o conhecimento público. Extrair elementos cognoscitivos da cultura, esquivar-se de explorá-los filosoficamente, conceituá-los normativamente, elaborar a partir deles princípios que retornarão à base cultural, é um circuito que vai muito além que elaborar princípios políticos para distribuição de bens; mais que uma teoria da justiça, essa é uma teoria sobre a reflexão política, sobre a forma e condições da reflexão pública. E isso nos conduz à segunda característica da Teoria da justiça a nós aqui relevante: a justiça como eqüidade constitui uma reflexão sobre a reflexão política. Ela reúne em si o que Rawls chama de sabedoria política, a submissão da política ao crivo da análise racional, a partir de uma perspectiva histórica, situada entre um conservadorismo rabugento e um ímpeto idealizado de uma realidade que perdeu sua ligação com a atualidade. De outra maneira, é também o reconhecimento dos condicionamentos ao conhecer, raciocinar, idealizar, agir, tornar público, e ser movido pelo possível, este possível como sendo o resultado metodológico das condições sobre as quais pode apoiarse a ação política, sob a forma de uma provisoriedade estratégica.

São essas características, tomadas como constituintes da sabedoria política, que nos interessam, e que nos darão fundamento à normatividade metódica da política liberal. Saber evitar a decisão final sobre a própria visão de mundo é um 
princípio metodológico fundamental, princípio que conduz o esforço teórico de Rawls, e que faz da postura política uma postura eminentemente reflexiva. É, em outras palavras, também aplicar o princípio de tolerância à filosofia (Rawls, 2000b, p. 268), ${ }^{16}$ bem como implica reconhecer que somente algumas questões políticas poderão ser resolvidas satisfatoriamente, e que sabedoria consiste em saber identificar essas questões (Rawls, 2000b, p. 274). ${ }^{17}$

\section{Referências}

RAWLS, John. Uma teoria da justiça. São Paulo: Martins Fontes, 1997a. . O Liberalismo Político. São Paulo: Ática, 2000a.

. Justiça como eqüidade, uma reformulação. São Paulo: Martins Fontes, 2003a.

A Theory of Justice. Massachusetts: The Belknap Press of Harvard University Press. 1997b.

. Political Liberalism. New York: Columbia University Press, 1996.

. Justice as Fairness, a Restatement. Cambridge: Harvard University Press, 2003b.

. John Rawls Collected Papers. Massachusetts: Harvard University Press, 1999.

O direito dos povos. São Paulo: Martins Fontes, 2001.

. Justiça e democracia. São Paulo: Martins Fontes, 2000b.

. Lectures on the History of Moral Philosophy. Cambridge: Harvard University Press, 2000c.

WALDRON, Jeremy. Theoretical Foundations of Liberalism. In: The Philosophical Quarterly, 37: 127-50, abr. 1987.

${ }_{16}$ "We simply apply the principle of toleration to philosophy itself" (Rawls, 1999, p. 435).

"We should not assume that there exist reasonable and generally acceptable answers for all or even for many questions of political justice that might be asked. Rather, we must be prepared to accept the fact that only a few such questions can be satisfactorily resolved. Political wisdom consists in identifying those few, and among them the most urgent" (Rawls, 1999, p. 438). 